\title{
REPRESENTAÇÕES SOCIAIS DA SURDEZ
}

\author{
SOCIAL REPRESENTATIONS OF THE DEAFNESS
}

Zélia Z L C Bittencourt ${ }^{1}$, Ana Paula Montagnoli²

\begin{abstract}
'Docente. CEPRE e Curso de Fonoaudiologia. ${ }^{2}$ Aprimoranda em Serviço Social. Centro de Estudos e Pesquisas em Reabilitação Prof. Dr. Gabriel Porto. Faculdade de Ciências Médicas - UNICAMP

CorrespondênciA: Profa. Dra. Zélia Z L C Bittencourt. Rua José Morano, 506 - CEP 13100-055 Campinas - S.P.

Fone: 19-3521-8817 FAX: 19-3252-8287 / Email: zeliaz@fcm.unicamp.br
\end{abstract}

Bittencourt ZZLC, Montagnoli AP. Representações sociais da surdez. Medicina (Ribeirão Preto) 2007; 40 (2): 243-9.

RESUMO: O objetivo deste estudo foi conhecer as representações sociais e o impacto da surdez no cotidiano de familiares de crianças surdas. Métodos: Nesta investigação adotou-se a metodologia qualitativa utilizando-se entrevistas com questões abertas como ferramenta de coleta de dados. A amostra contou com 15 familiares (pais ou mães) de crianças surdas atendidas em um serviço de reabilitação. Resultados: A surdez foi representada como "um fardo", "sofrimento", "transtorno", "sobrecarga" gerando "sentimento de culpa", e dificuldade de aceitação por parte da família, enquanto a reabilitação remete à idéias de "socialização", "respeito' e "aceitação" no meio social. Conclusão: O conhecimento das representações e expectativas dos pais trouxe subsídios para novas ações que incluam maior atenção às famílias, incentivo à participação em grupos de pais, visando a troca de experiências.

Descritores: Surdez. Reabilitação de Deficientes Auditivos. Serviços de Reabilitação. Família.

\section{1- INTRODUÇÃO}

O conceito de surdez e da pessoa surda vem sofrendo mudanças no decorrer da história e particularmente nas últimas décadas, importantes avanços políticos vêem ocorrendo nesta área, difundindo no Brasil a idéia da pessoa surda, com ênfase na "diferença" e não mais na "deficiência" ${ }^{1}$. Este reconhecimento político da surdez pode ser traduzido em ações que considerem os direitos dos surdos enquanto cidadãos, com os recortes de suas identidades, língua, comunidade e cultura entre outros. ${ }^{2}$

A pessoa surda pode ser definida como aquela que vivencia um déficit de audição que a impede de adquirir de maneira natural, a língua oral/auditiva usada na comunidade majoritária, e que constrói sua iden- tidade calcada nesta diferença, utilizando-se de estratégias cognitivas e de manifestações comportamentais e culturais diferentes da maioria das pessoas que ouvem $^{2}$. Todavia, apesar dos avanços observados nas discussões teórico-conceituais sobre este tema, ainda percebe-se que a sociedade tem muita dificuldade em mudar seus valores e assimilar novos conceitos.

A problemática da surdez provoca grande impacto e alterações na dinâmica e nos papéis familiares, mobilizando a expectativa que os pais têm sobre este filho. É inegável o importante papel da família no desenvolvimento da criança, especialmente aquela que apresenta algum tipo de deficiência.

A surdez tem sido analisada como um obstáculo na comunicação, que isola a criança da sua família e da comunidade ouvinte, e entendida como um tipo 
de privação sensorial cujos efeitos estão associados aos significados produzidos pela sociedade através de práticas discursivas onde se efetivam as caracterizações estereotipadas da pessoa surda, a quem são atribuídos traços como pensamento concreto, elaboração conceitual rudimentar, baixa sociabilidade, rigidez, imaturidade emocional entre outros. Tais estereótipos são reforçados em uma sociedade majoritariamente ouvinte, que tem dificuldade de conviver com as diferenças $^{3,4}$.

O Centro de Estudos e Pesquisas em Reabilitação Prof Dr Gabriel Porto - CEPRE - atende pessoas surdas e seus familiares, em todas as fases de suas vidas, desde a mais tenra idade até a adolescência e idade adulta, onde são acompanhados em vários programas multidisciplinares. Em consonância com as transformações políticas na área da surdez, enfatiza o bilingüismo, trabalhando a identidade desta minoria lingüística e cultural. Neste sentido, adota a Língua Brasileira de Sinais (LIBRAS) como forma de promover a inclusão da pessoa surda na sociedade, proporcionando-lhe uma melhor qualidade de vida.

A Legislação Brasileira determina a inclusão de pessoas com necessidades educacionais especiais na rede regular de ensino, todavia ainda há muitos problemas e dificuldades para a realização de sua efetiva implantação. Fica evidente que apesar dos avanços nesta área, a surdez não pode ser reduzida a aspectos racionais, devendo ser entendidas e consideradas as influências socioculturais e os valores de determinada sociedade, traduzidos na legislação que reconhece a LIBRAS, como forma de comunicação das comunidades surdas. Recentemente observou-se novo salto qualitativo nesta área com a adoção e a inclusão da LIBRAS nos cursos de formação de professores como disciplina curricular obrigatória. (Decreto No 5626 de 22/12/2005).

Conforme o Censo Demográfico de $2000^{5}$, no Brasil existem mais de 5.700.000 surdos, que na maior parte só são diagnosticados em torno dos dois anos de idade, o que de acordo com o Joint Committee on Infant Hearing ${ }^{6}$, é considerado tardio, uma vez que se preconiza que o diagnóstico da perda auditiva deve ser realizado até os 3 meses de idade e a intervenção até os 6 meses. Quanto mais cedo for detectado qualquer problema auditivo, mais eficientes serão as condutas a serem adotadas. A agilidade na reabilitação auditiva é conveniente, visto que há período de prontidão para o aprendizado podendo desta forma, a privação auditiva interferir no processo ${ }^{7}$.
O trabalho de habilitação e reabilitação auditiva possibilita à criança fazer o maior uso possível do eventual resíduo auditivo. Muitas dúvidas e sentimentos fazem parte da vida da família durante o processo terapêutico, especialmente os relacionados à comunicação. A família e a criança mergulharão no mundo da comunicação, e no cotidiano serão orientados a proporcionar experiências que favoreçam o desenvolvimento da audição e linguagem ${ }^{8}$ propiciando a constante prática em ouvir, chamando a atenção da criança para o mundo sonoro, apresentando o ruído com o objeto correspondente. ${ }^{9}$ Nesse processo os pais são orientados sobre a importância de seu papel no desenvolvimento da linguagem e das habilidades auditivas da criança, bem como sobre a função dos profissionais envolvidos no processo de educação de surdos, respondendo, portanto, às necessidades das crianças e de suas famílias. A natureza e o grau de comprometimento dos pais e demais familiares no processo de reabilitação da criança com deficiência auditiva são decisivos para o sucesso de seu desenvolvimento. Neste sentido, torna-se fundamental investigar o grau de conhecimento dos pais sobre alguns aspectos da deficiência auditiva dos filhos, pois a representação que estes têm de seu filho surdo e da surdez poderão influenciar no processo terapêutico e pedagógico.

A temática das representações sociais tem constituído um campo fértil de pesquisas na área da saúde. Estudos sobre as percepções, conhecimentos e representações sociais têm trazido importantes contribuições de diversos autores à compreensão do processo saúde-doença, visto que têm como base a experiência vivida das pessoas, e são produzidas pelas interações de grupos sociais, refletindo assuntos que são objeto de seu cotidiano ${ }^{10}$.

As representações sociais acontecem em todas as ocasiões e lugares onde pessoas se encontram e se comunicam, onde se desenvolve a vida cotidiana e nos universos de opiniões característicos de diferentes segmentos e grupos populacionais ${ }^{11}$. Tais discursos não são neutros e geram conseqüências na vida das pessoas.

Representações sociais são, portanto, modalidades de conhecimento prático, orientadas para a comunicação e para a compreensão do contexto social em que vivemos ${ }^{12}$ e se manifestam através de imagens, conceitos, categorias, teorias, mas não se reduzem somente aos componentes cognitivos. Desta forma, são fenômenos sociais gerados a partir de funções simbólicas e ideológicas e das formas de comunicação onde circulam ${ }^{13}$. 
Canesqui ${ }^{14}$ reforça a idéia de que as representações da saúde e doença se apóiam em conceitos, símbolos e estruturas interiorizadas, conforme os grupos sociais a que pertencem. Minayo ${ }^{15}$ toma as representações como senso comum, idéias, imagens, concepções e visões de mundo. Para esta autora as representações sociais "estão pensadas em relação às bases materiais que a engendram: de um lado temos o homem que é produto de seu produto: as estruturas da sociedade criam o seu ponto de partida; de outro, temos que este homem constrói a história dentro das condições recebidas ultrapassando-as e inscreve sua significação sobre toda a parte, em todo o tempo e a ordem das coisas".

A presente investigação teve como propósito conhecer as representações e o impacto do diagnóstico da surdez no cotidiano de familiares de pessoas surdas atendidas em um serviço de reabilitação.

\section{2- CASUÍSTICA E MÉTODOS}

Trata-se de uma investigação de caráter qualitativo, realizada no acompanhamento de pais e mães de pessoas surdas tendo como cenário o Centro de Estudos e Pesquisas em Reabilitação "Prof. Dr. Gabriel Porto" da Faculdade de Ciências Médicas da UNICAMP. Foram sujeitos do estudo 15 familiares (mães e pais) de crianças e adolescentes surdos, que freqüentavam o programa de reabilitação no ano de 2005. Os familiares foram convidados a participar voluntariamente da pesquisa, sendo respeitado o protocolo ético. Com o objetivo de obtermos o material verbal que indicassem as representações sociais da surdez, utilizou-se a técnica de entrevista em situação individual. As entrevistas foram gravadas com o consentimento dos entrevistados. O estudo constou de um roteiro com questões abertas norteadoras (ANEXO I), que não foram usadas rigidamente a fim de se evitar o engessamento dos relatos. Além de dados de identificação dos entrevistados foram incluídas as variáveis: sexo, idade, situação civil, escolaridade, profissão e renda, constituindo o perfil dos entrevistados. Na empreitada da pesquisa, seguiram-se as etapas da análise de conteúdo ${ }^{15,16}$, que consistiu em préanálise, exploração do material, tratamento dos resultados e interpretação. A partir dos dados coletados, foi possível estabelecer categorias analíticas de acordo com os núcleos temáticos emergentes: $\mathrm{O}$ impacto do diagnóstico da surdez; A convivência com a surdez; O significado da reabilitação.

\section{3- RESULTADOS E DISCUSSÃO}

Observou-se que $93,3 \%$ dos familiares entrevistados eram do sexo feminino, todos ouvintes, em sua maior parte constituída por donas de casa, idade variando de 30 a 62 anos, com idade média de 44 anos. Estes dados evidenciam o papel da mulher como responsável pela assistência, cuidados com a saúde do filho, além de ser a pessoa que melhor se comunica com o filho surdo, tanto pelas características próprias do contato materno como pelo fato de freqüentar o curso de línguas de sinais.

A maioria entrevistada era constituída por analfabetos funcionais $(46,6 \%)$, seguindo-se por $20 \%$ de pessoas que freqüentaram o ensino fundamental e $33,4 \%$ o ensino médio incompleto. Quanto ao estado civil $80,0 \%$ dos entrevistados eram casados ou viviam relação consensual e 20,0\% era constituído de solteiros, separados ou viúvos. No que se refere à renda familiar, a maioria $(60,0 \%)$ encontra-se na faixa de até três salários mínimos (Tabela I).

Tabela I - Perfil da amostra ( $\mathbf{N}=\mathbf{1 5})$

\begin{tabular}{lrr}
\hline Variável & $N$ & $\%$ \\
\hline Sexo & & \\
Masculino & 1 & 6,7 \\
Feminino & 14 & 93,3 \\
Idade & 30 a 62 anos & média 44 anos
\end{tabular}

Escolaridade

Analfabeto funcional $7 \quad 46,6$

Ensino fundamental 3 20,0

Ensino médio incompleto

5

33,4

Estado civil

Solteiros, separados, viuvos

Casados/união estável

20,0

Profissão

Do lar

80,0

Cozinheira, vendedora

12

13,3

Frentista

1

6,7

Renda

1 a $3 \mathrm{sm}$

60,0

3 a $5 \mathrm{sm}$

9

33,4

$>5 \mathrm{sm}$

5

6,7 
A amostra estudada, portanto foi significativa por refletir o perfil da população atendida em um serviço de reabilitação conveniado ao Sistema Único de Saúde, constituída por pessoas casadas, de baixa renda e baixa escolaridade, levando-se em conta os vários modelos de família, com valores e influências socioculturais próprias do cenário social em que vivem.

Nos achados qualitativos, os relatos e reflexões surgidos no decorrer da investigação permitiram-nos delinear o movimento das relações sociais e os significados que os pais atribuem às suas vidas, na trajetória de busca de cuidados de um filho surdo.

Considerando-se a categoria $\mathbf{O}$ impacto do diagnóstico da surdez foi possível depreender que o desconhecimento dos pais sobre a surdez contribuiu consideravelmente para a dificuldade de aceitação do diagnóstico, que após o início da participação em serviços de reabilitação e o contato com o grupo de iguais, foi pouco a pouco sendo superado.

Conforme os relatos, o impacto do diagnóstico da surdez na vida cotidiana dos familiares se revelou muitas vezes como "o fim do mundo", gerando dificuldade de aceitação por parte da família, que desconhece outra forma de comunicação que não seja a fala. A fase inicial do conhecimento do diagnóstico foi para muitos entrevistados, cercada por sentimentos de tristeza e depressão.

Alguns autores referem que a confirmação do diagnóstico pode ser vista como um golpe pessoal, através do qual os pais buscam uma causa e uma explicação para a deficiência do filho ${ }^{17}$. Sabe-se, ainda que em famílias que contam com pessoas com algum tipo de deficiência, não raramente instala-se uma crise familiar exigindo mudanças no comportamento dos demais membros ${ }^{4}$. Entre os achados da investigação, observou-se que a surdez foi representada como "um fardo", "sofrimento", gerando "sentimento de culpa", "transtorno", "sobrecarga".

"Quando eu descobri, acabou o mundo, mas o tempo me mostrou que minha filha não era a única...”

"Eu não aceitava, tinha depressão, nem na aula de LIBRAS eu queria aprender. Agora estou aceitando mais".

"A gente fica triste por ter um filho assim... me sinto culpada e não me sinto bem".

O estresse vivenciado pelos familiares devido à atenção especial e à relação de dependência que se estabelece entre os pais e a criança surda, também tem sido considerado um fator agravante no sentimento de "sobrecarga" já referido. Vários estudos ${ }^{18}$ comprovam que o nível de estresse é mais evidente em famílias de crianças deficientes.

"Tive muitos problemas de saúde, fiquei muito sobrecarregada, muita dificuldade para aceitar a surdez (...)”.

O conteúdo da categoria A convivência com a surdez, revela que no cotidiano, os sentimentos dos pais da criança surda passam por quatro estágios a partir do diagnóstico: inicialmente a negação, resistência, afirmação e finalmente a aceitação ${ }^{4}$. Na fase de aceitação, os pais utilizam em seu discurso expressões como "vitória", "luta" e "superação" na vivência com o indivíduo surdo.

Observou-se ainda a distinção entre os termos "doente" e "diferente" assim como a atribuição de grande parte de seu sofrimento à sociedade discriminatória e preconceituosa, que segrega o deficiente, tratando-o como incapacitado. Da mesma forma, alguns pais se recusavam a uma maior participação no meio social, por sentirem-se constrangidos diante da deficiência do filho. Outros, ainda anulavam-se em prol da criança, agindo de forma superprotetora, transferindo para a sociedade a culpa que muitas vezes sentem pela deficiência do filho.

"É muito difícil, cada dia é uma superação... Hoje participo, supero, e ela esta bem".

"Ela não é uma pessoa doente... a deficiência representa luta, persistência e paciência".

"Para mim a deficiência não é o problema e sim a sociedade".

Quanto ao significado da reabilitação, em vários depoimentos observou-se que o processo de reabilitação foi referido como um aspecto fundante na retomada da vida social do surdo. Devido à privação lingüística imposta aos surdos pelas próprias famílias, visto que a maioria dos surdos são membros de famílias ouvintes, que em geral desconhecem ou não aceitam o uso da língua de sinais, estes ingressam na escola com um pobre cabedal de conhecimento do mundo comparado com as crianças ouvintes. Todavia, os relatos apontaram para questões como "respeito", "aceitação", "socialização", "integração" e "evolução" que estão diretamente relacionadas ao progresso conseguido com a reabilitação. 
A escola, além de ser o local de alfabetização, também se mostra como importante possibilidade de aprendizado para a vida social, e nesse processo os pais passam a conhecer melhor o potencial dos filhos, dando-lhes mais valor ${ }^{4}$.

"Ajuda na socialização e integração com as pessoas, mostra que ela é capaz”.

"É uma coisa boa para ela e para mim, é evolução e aprendizagem”.

"A escola é importante para integrar ela o mais rápido possível no meio social”.

No decorrer do processo terapêutico e pedagógico da criança surda, freqüentemente se observa certa cobrança dos pais em relação ao desenvolvimento da fala e da linguagem do filho, uma vez que esse é o maior anseio da família. Nesse contexto, com o intenso desejo de que o filho desenvolva a fala, alguns pais passam a enxergar a linguagem de sinais com discriminação, enquanto outros, vêem na LIBRAS uma possibilidade para facilitar a inserção social da criança surda. Da mesma forma, a utilização do aparelho auditivo e sua representação, pode vir a desencadear sentimentos ambivalentes para a família do indivíduo surdo, pois tanto desperta a esperança da retomada da audição, quanto à concretização da surdez, podendo em alguns casos se observar um retrocesso no processo de aceitação. As tradicionais preocupações dos pais com relação ao sucesso, aceitação social e independência dos filhos podem emergir, gerando sérias crises com a descoberta de que a evolução da criança dentro do processo de reabilitação é limitada.
"O uso do aparelho... Foi ela falar e os sinais que ela faz com os colegas".

"O aparelho melhorou a comunicação entre ela e a família".

"O aparelho ajudou a desenvolver a fala, deu ânimo".

\section{4- CONSIDERAÇÕES FINAIS}

Os dados produzidos neste estudo revelaram que o impacto causado pelo diagnóstico de surdez na família da pessoa surda foi representado como um acontecimento "negativo", marcado pela "tristeza e sofrimento". As convivências com a surdez e o início do processo de reabilitação apresentaram novas situações antes não experimentadas pelos familiares, como o contato com outros indivíduos surdos, possibilitando um espaço para o compartilhamento de sentimentos, dúvidas e anseios. O processo de reabilitação aflorou sentimentos contraditórios nos pais, tanto pela utilização da língua de sinais como forma de comunicação, como pela expectativa da fala ou ainda pelo uso do aparelho auditivo, que concretizam e reafirmam a diferença do filho.

Neste sentido, o conhecimento das representações e das expectativas dos pais quanto ao desenvolvimento de seus filhos e suas reais possibilidades foi fundamental para subsidiar o planejamento de políticas institucionais, ações e estratégias inovadoras que incluam maior atenção e orientação às famílias e à rede de relações da pessoa surda, além de outras iniciativas como a formação de grupos de pais com vistas ao apoio e a troca de experiências.

Bittencourt ZZLC, Montagnoli AP. Social representations of the deafness. Medicina (Ribeirão Preto) 2007; 40 (2): $243-9$.

ABSTRACT: The aim of this study was to understand the social representations and the impact of the deafness in the daily life of families with deaf children. Methods: To reach this aim, qualitative methodology was adopted using interviews with open-ended questions as tool to collect data. Fifteen parents of deaf children who attended a rehabilitation center were interviewed. Results: The deafness was represented as a "weight", "a suffering", "a upset", "a overload", producing guilty conscience and difficulty of acceptance by these families, while rehabilitation refer to ideas like "socialization", "respect" and "acceptance" in the social environment. Conclusion: The knowledge of the representations and expectations of the deaf people parents, brought back information to formulate new ways of assistance to them. Moreover, the living together with the deafness and other deaf people made possible to them share their feelings, doubts and expectations.

Keywords: Deafness. Rehabilitation of Hearing Impaired. Rehabilitation Services. Family. 


\section{REFERÊNCIAS}

1 - Silva IR. As representações do surdo na escola e na família: entre a (in) visibilização da diferença e da "deficiência" [Tese de Doutorado], Campinas: Instituto de Estudos de Linguagem -UNICAMP; 2005.

2 - Limeira de Sá N. Identidades surdas: os estudos surdos. Rev FENEIS, julho 2002:26-8.

3 - Góes MCR. Linguagem surdez e educação. São Paulo: Editora Autores Associados; 1996.

4 - Boscolo CC, Santos TMM. A deficiência auditiva e a família: sentimentos e expectativas de um grupo de pais de crianças com deficiências da audição. Distúrb Comun 2005; 17 (1): 69 75.

5 - Neri M. Diversidade: retratos da deficiência no Brasil. Rio de Janeiro: FGV/IBRE, CPAS; 2003.

6 - Joint Committee on Infant Hearing. Position statement. Audiol Today 1994; 6: 6-9.

7 - Scaranello CA. Reabilitação auditiva pós-implante coclear. Medicina (Ribeirão Preto) 2005; 38: 273-8.

8 - Brazorotto JS. A terapia fonoaudiológica da criança surda. In: Bevilacqua MC, Moret AL (org).Deficiência auditiva: conversando com familiares e profissionais de saúde.São José dos Campos: Pulso; 2005. p.203-23.

9 - Lima MCMP, Boechat HA, Tega LM. Habilitação fonoaudiológica da surdez: uma experiência no Cepre/FCM/Unicamp In: Silva IR, Kauchakje S, Gesueli Z M (org). Cidadania, surdez e linguagem: desafios e realidades. São Paulo: Plexus Editora; 2003 p. $41-9$.
10 - Nunes ED. A doença como processo social. In Canesqui AM. Ciências sociais para o ensino médico. São Paulo: HucitecFAPESP; 2000. p. 217-28.

11 - Sá CP. Representações sociais: o conceito e o estado atual da teoria. In: Spink JS (org). O conhecimento no cotidiano: as representações sociais na perspectiva da psicologia social. São Paulo: Brasiliense; 1999. p.19-45.

12 - Jodelet D. La representación social: fenómenos, concepto y teoría. In: Moscovici S (org) Psicología social. Barcelona: Paídos; 1985. p. 469-94.

13 - Spink MJP. O conceito de representação social na abordagem psicossocial. Cad Saúde Pública 1993; 9 (3): 300-8.

14 - Canesqui AM. Os estudos de antropologia da saúde/doença no Brasil na década de 1990. Ciênc Saúde Coletiva 2003; 8 (1): 109-24.

15 - Minayo MCS. O desafio do conhecimento: pesquisa qualitativa em saúde. São Paulo Rio de Janeiro: Hucitec-Abrasco; 1996.

16 - Bardin L. Análise de conteúdo. Lisboa, Edições 70; 1988.

17 - Brito AMW, Dessen MA. Crianças surdas e suas famílias: um panorama geral. Psicol Reflex Crit 1999; 12:1-15.

18 - Dyson LL. Response to the presence of a child with disabilities: parental stress and family functioning over time. Am J Ment Retardation, 1993; 98(2): 207-18.

Recebido em 19/01/2007

Aprovado em 05/03/2007 


\section{ANEXO I}

\section{DADOS DE IDENTIFICAÇÃO DO FAMILIAR}

Nome:

Idade: Sexo:

Escolaridade:

Escolarida
Profissão: Situação civil: Renda:

\section{QUESTÕES NORTEADORAS DA INVESTIGAÇÃO:}

1- Quando e como você soube da surdez de seu filho?

2- Como foi para você o momento do diagnóstico?

3- Qual o sentido da surdez /deficiência auditiva para você? O que representa a surdez para você?

4- Como tem sido a convivência com a surdez de um filho?

5- Quando você procurou o serviço de reabilitação? Quem a encaminhou?

6- Qual o significado da reabilitação para você? O que representou na sua vida e na vida de seu filho?

7- Quais os acontecimentos ou mudanças importantes observadas após o início da reabilitação? 